\title{
Latitudinal variation rate of geomagnetic cutoff rigidity in the active Chilean convergent margin
}

\author{
Enrique G. Cordaro $^{1,2}$, Patricio Venegas ${ }^{1,3}$, and David Laroze La $^{4,5}$ \\ ${ }^{1}$ Observatorios de Radiación Cósmica, Universidad de Chile, Casilla 487-3, Santiago, Chile \\ ${ }^{2}$ Facultad de Ingeniería, Universidad Autónoma de Chile, Pedro de Valdivia 425, Santiago, Chile \\ ${ }^{3}$ Departamento de Geofísica, Universidad de Chile, Blanco Encalada 2002, Santiago, Chile \\ ${ }^{4}$ Instituto de Alta Investigación, CEDENNA, Universidad de Tarapacá, Casilla 7D, Arica, Chile \\ ${ }^{5}$ School of Physical Sciences and Nanotechnology, Yachay Tech University, 00119 Urcuquí, Ecuador
}

Correspondence: Enrique G. Cordaro (ecordaro@dfi.uchile.cl)

Received: 12 September 2017 - Revised: 10 January 2018 - Accepted: 24 January 2018 - Published: 1 March 2018

\begin{abstract}
We present a different view of secular variation of the Earth's magnetic field, through the variations in the threshold rigidity known as the variation rate of geomagnetic cutoff rigidity (VRc). As the geomagnetic cutoff rigidity (Rc) lets us differentiate between charged particle trajectories arriving at the Earth and the Earth's magnetic field, we used the VRc to look for internal variations in the latter, close to the $70^{\circ}$ south meridian. Due to the fact that the empirical data of total magnetic field $\mathrm{BF}$ and vertical magnetic field $\mathrm{Bz}$ obtained at Putre (OP) and Los Cerrillos (OLC) stations are consistent with the displacement of the South Atlantic magnetic anomaly (SAMA), we detected that the VRc does not fully correlate to SAMA in central Chile. Besides, the lower section of VRc seems to correlate perfectly with important geological features, like the flat slab in the active Chilean convergent margin. Based on this, we next focused our attention on the empirical variations of the vertical component of the magnetic field $\mathrm{Bz}$, recorded in OP prior to the Maule earthquake in 2010, which occurred in the middle of the Chilean flat slab. We found a jump in Bz values and main frequencies from 3.510 to $5.860 \mu \mathrm{Hz}$, in the second derivative of $\mathrm{Bz}$, which corresponds to similar magnetic behavior found by other research groups, but at lower frequency ranges. Then, we extended this analysis to other relevant subduction seismic events, like Sumatra in 2004 and Tohoku in 2011, using data from the Guam station. Similar records and the main frequencies before each event were found. Thus, these results seem to show that magnetic anomalies recorded on different timescales, as VRc (decades) and Bz (days), may
\end{abstract}

correlate with some geological events, as the lithosphereatmosphere-ionosphere coupling (LAIC).

Keywords. Geomagnetism and paleomagnetism (time variations - secular and long term)

\section{Introduction}

The arrival of charged particles to the Earth can be estimated from their trajectories. The minimum momentum per charge unit that a particle must possess to reach a specific point on the Earth's surface is defined as the vertical geomagnetic cutoff rigidity $(\mathrm{Rc})$, which depends on the geometric configuration and extent of the Earth's magnetic field (Fichtner et al., 2012). Due to the fact that Rc has a spatial distribution similar to the difference between the horizontal and vertical magnetic field $(\delta B)$, in some cases it is possible to study the Rc and the variation rate of geomagnetic cutoff rigidity (VRc) as a measure of the secular variation of the Earth's magnetic field (Herbst et al., 2013).

The work of Herbst et al. (2013) shows that the lower values in VRc are located in an area in the south of Chile, in midlatitudes, in spite of the fact that the presence of the South Atlantic magnetic anomaly (SAMA) is extended to equatorial areas. In this work, we seek to find a relation with the Chilean flat slab trench (which corresponds to the zone where the plate of Nazca subducts to the same depth below the South American plate), due to the fact that significant topographic conditions in the active convergent Chilean margin are capable of altering the genesis of the secular varia- 
tions in the core-mantle boundary (CMB), as is the case of the subduction of the Nazca plate under the South American plate, which reaches the $\mathrm{CMB}$ and produces a downwelling at the CMB (Yoshida, 2008; Lassak et al., 2010; Soldati et al., 2012).

This extension of the Chilean flat slab trench towards the CMB is important because the latest research shows that the role played by CMB topography is closely related to the evolution of geodynamic and in particular to the existence of SAMA (Gubbins, 1988; Olsen et al., 2014; Tarduno et al., 2015; Pavón-Carrasco and De Santis, 2016). In addition, as the radial component of the Earth's magnetic field can be used as a measure of the variations in the CMB in periods of time of several months or years, we looked for significant variations in the geomagnetic spectra associated with other major geological events in the Chilean margin, as the latest research shows a statistically significant relation between geomagnetism and earthquakes (Hayakawa and Molchanov, 2002; Pulinets and Boyarchuk, 2004; Varotsos, 2005; Hayakawa et al., 2007, 2015; Molchanov and Hayakawa, 2008; Liu, 2009; De Santis et al., 2015, 2017; Contoyiannis et al., 2016; Potirakis et al., 2016a, b).

It should be noted that most investigations of magnetism and earthquakes have not been conclusive because of the use of magnetic records that are heavily governed by the external conditions of the ionosphere, making the results meaningless in the geodynamic context (Thomas et al., 2009; Love and Thomas, 2013; Masci and Thomas, 2015). Despite this, there is a great amount of recent and rigorous research that has shown a statistical relation between magnetism and earthquakes, and thus, this effect could not be negligible in other magnetic properties, such as the Rc or the study of particle flux at Earth's ground level (Hayakawa et al., 2015; Contoyiannis et al., 2016; Potirakis et al., 2016a, b; De Santis et al., 2017; Oikonomou et al., 2017).

Other authors have detected links between the geomagnetic field and its variations before earthquakes: Florindo et al. (1996) proposed a cause-effect relation between highintensity earthquakes and the consequent appearance of a geomagnetic jump through a timespan of 2 years before the quake, while Kopytenko et al. (2012) found secular anomalies on the geomagnetic field which started 3 years before the 2011 Tohoku earthquake. Takla et al. (2013) found an increase of $5 \mathrm{nT}$ around the vicinity of the epicenter of the 2011 Tohoku earthquake, as well as a possible anomaly a couple of weeks prior to the tectonic movement. Hayakawa et al. (2015) and Contoyiannis et al. (2016) found a statistical relation between magnetic disturbances and earthquakes, with a transition phase in the behavior of magnetic field (anomalies in the ultralow-frequency band on the order of millihertz), where the critical point correspond to dates close to the 2011 Tohoku earthquake. Potirakis et al. (2016a) found similar statistical characteristics in the 2013 Kobe earthquake. Donner et al. (2015), showed that when rock is stressed, magnetic variations appear, where each frequency

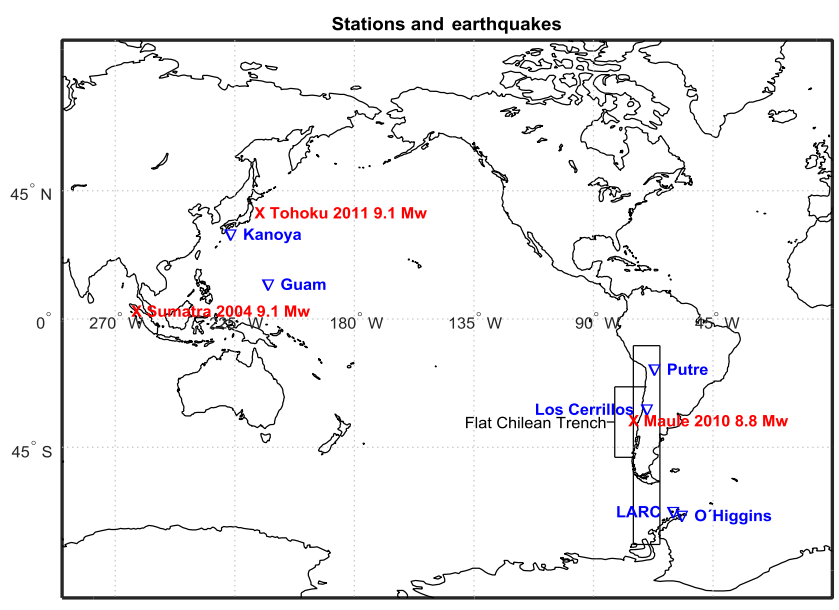

Figure 1. Observatories map of magnetometers and cosmic rays (blue triangles): the OP, OLC, LARC, O'Higgins Geomagnetic Observatory (OH), Guam (GUA) and Kanoya (KNY). A red X marks the earthquake events (Sumatra, Maule, Japan) with $M_{\mathrm{W}}$ above 8.8. (2004-2011). Rectangle represents the area covered by cutoff rigidity study. The smaller left rectangle indicates the flat Chilean trench.

range is associated with stages prior to the main failure. Furthermore, De Santis et al. (2017) postulated a statistical correlation between magnetic anomalies and cumulative seismic events for the 2015 Nepal earthquake, using satellite data.

The details of the methodology and results are shown extensively in the next sections. Firstly, we analyze the values of the secular variations of the magnetic field obtained at two stations located $1700 \mathrm{~km}$ away from each other, near $70^{\circ} \mathrm{W}$ longitude and between 18 and $33^{\circ} \mathrm{S}$ latitude. The SAMA center is also located in this area, $1700 \mathrm{~km}$ away from both observatories. The rest of this paper is organized as follows: Sect. 2 presents the monitoring stations and data used, while Sect. 3 briefly shows the standard method, in which an experimental procedure using geomagnetic data was developed to compute Rc and its variations, magnetic measurement and behavior prior to the 2004 Sumatra, 2010 Maule and 2011 Tohoku earthquakes. This section also describes the spectral analysis in the period before to the earthquakes mentioned above and the spectrogram analysis carried out for the Maule event. Finally, both the discussion and the conclusion are found in Sect. 4.

\section{Magnetic field and stations}

The main stations used in this study are the Putre Observatory (OP), the Los Cerrillos Observatory (OLC) and the Antarctic Observatory (Laboratorio Antártico de Radiación Cósmica: LARC). The first two are equipped with fluxgate magnetometers and counters (with PUT and CER the IAGA codes respectively), as well as muon telescopes and neutron monitors. However, the LARC station, in addition to one 
Table 1. Technical specifications of the Chile, Guam and Kanoya stations used (data from Anand et al., 1968 and Cordaro et al., 2012).

\begin{tabular}{|c|c|c|c|c|c|c|c|}
\hline Observatory & Location & $\begin{array}{l}\text { Geographical } \\
\text { coordinate }\end{array}$ & $\begin{array}{r}\text { Altitude/ } \\
\text { depth } \\
\text { (ma.s.l.) }\end{array}$ & $\begin{array}{r}\text { Atmospheric } \\
\left(\mathrm{g} \mathrm{cm}^{-2}\right)\end{array}$ & Instruments & Time & $\begin{array}{r}\text { Rigidity } \\
(\mathrm{GV})\end{array}$ \\
\hline $\begin{array}{l}\text { PUTRE } \\
\text { (OP) }\end{array}$ & $\begin{array}{l}\text { Andes, } \\
\text { Chile }\end{array}$ & $\begin{array}{l}18^{\circ} 11^{\prime} 47.8^{\prime \prime} \mathrm{S} \\
69^{\circ} 33^{\prime} 10.9^{\prime \prime} \mathrm{W}\end{array}$ & 3600 & 666 & $\begin{array}{l}\text { Magnetometer, UCLA-Vectorial-Flux } \\
\text { Gate (data per second) } \\
\text { Muon telescope (data per second), } \\
3 \text { channels. } \\
\text { Neutron monitor IGY (data per } \\
\text { second), } 3 \text { channels, } \\
\text { He } 3 \text { (data per second). } \\
\text { UTC by GPS receiver. }\end{array}$ & 2003-2017 & $11.73(2010)$ \\
\hline $\begin{array}{l}\text { Los Cerrillos } \\
\text { (OLC) }\end{array}$ & $\begin{array}{l}\text { Santiago de Chile, } \\
\text { Chile }\end{array}$ & $\begin{array}{l}33^{\circ} 29^{\prime} 42.2^{\prime \prime} \mathrm{S} \\
70^{\circ} 42^{\prime} 59.81^{\prime \prime} \mathrm{W}\end{array}$ & 570 & 955 & $\begin{array}{l}\text { Magnetometer, UCLA-Vectorial-Flux } \\
\text { Gate (data per second). } \\
\text { Multi-directional muon telescope (data } \\
\text { per second), } 7 \text { channels. } \\
\text { Neutron monitor } 6 \text { NM64 (data per sec- } \\
\text { ond), } 3 \text { channels, BF-3. } \\
\text { UTC by GPS receiver. }\end{array}$ & 1958-2017 & $9.53(2010)$ \\
\hline LARC & $\begin{array}{l}\text { King George } \\
\text { Island, Antarctic }\end{array}$ & $\begin{array}{l}62^{\circ} 12^{\prime} 9^{\prime \prime} \mathrm{S} \\
58^{\circ} 57^{\prime} 42^{\prime \prime} \mathrm{W}\end{array}$ & 40 & 980 & $\begin{array}{l}\text { Magnetometer, UCLA-Vectorial-Flux } \\
\text { Gate (data per second). } \\
\text { Neutron monitor } 6 \mathrm{NM} 64 \text { - BF-3BF-3 } \\
\text { (data per second), } 6 \text { channels. } \\
\text { Neutron monitor } 3 \mathrm{NM} 64 \text { - He-3, } \\
3 \text { channels (data per second). } \\
\text { Neutron monitor 3NM64 - He-3 } \\
\text { (data per second). } \\
\text { (Flux meter) } 3 \text { channels. } \\
\text { UTC by GPS receiver. }\end{array}$ & 1990-2017 & $2.71(2010)$ \\
\hline $\begin{array}{l}\text { Guam } \\
\text { (GUA) }\end{array}$ & Marianna Islands & $\begin{array}{l}13^{\circ} 35^{\prime} 24.0^{\prime \prime} \mathrm{N} \\
144^{\circ} 52^{\prime} 12.0^{\prime \prime} \mathrm{E}\end{array}$ & 140 & No info & $\begin{array}{l}\text { Magnetometer fluxgate } \\
\text { (data per minute) }\end{array}$ & No info & $16.9(1965)$ \\
\hline $\begin{array}{l}\text { Kanoya } \\
(\mathrm{KNY})\end{array}$ & $\begin{array}{l}\text { Kagoshima } \\
\text { Prefecture }\end{array}$ & $\begin{array}{l}31^{\circ} 25^{\prime} 27^{\prime \prime} \mathrm{N} \\
130^{\circ} 52^{\prime} 48^{\prime \prime} \mathrm{E}\end{array}$ & 107 & No info & $\begin{array}{l}\text { Magnetometer } \\
\text { (data per minute) }\end{array}$ & 1958-2017 & $\sim 13.2(2000)$ \\
\hline
\end{tabular}

Magnetic field secular variations seen from geomagnetic cutoff rigidity (VRc). Geomagnetic field and its relation with geological process. Latitudinal VRc and its relation with special points at the Chilean convergent margin. Similar frequencies found in radial component of magnetic field in three earthquakes. Results could be related with lithosphere-ionosphere-atmosphere coupling.

fluxgate magnetometer and a type 6 NMBF3 neutron monitor, also operates two state-of-the-art type $3 \mathrm{NM} \mathrm{He}$ neutron monitors. Besides, other two auxiliary stations were used to perform magnetic measurements: the Guam observatory and the O'Higgins observatory. The network's particle detectors calculate the average values per hour from samples per second and the magnetometers calculate the values per minute from data per second, while the auxiliary magnetometers have data per minute. Table 1 provides location, atmosphere depth, instrumentation and operation time details for all the abovementioned stations, while their location has also been marked on the map in Fig. 1 (see Cordaro et al. (2012) and Table 1 for geomagnetic rigidity cutoff and operation times). The total magnetic field and its components as recorded by the magnetometers at the OP and OLC observatories show a decrease in all geomagnetic components and a decreasing trend in the geomagnetic rigidity cutoff, since these stations are under the influence of SAMA. We have obtained three magnetic components, north, east and vertical (Bx, By and $\mathrm{Bz}$ respectively), as well as the total BF. For our analysis, we used the total magnetic field and the Bz component, under the hypothesis that their behavior on the surface is the continuation of the radial magnetic field and its variations generated in the core.

\section{Analysis results}

\subsection{Variation rate of geomagnetic cutoff rigidity (VRc) close to meridian $70^{\circ} \mathrm{W}$ in South America}

We calculated and evaluated the VRc in the vertical access of particles arriving at OP, OLC and LARC, as seen in Fig. 2. At OP, we confirmed an in situ lower increase of cosmic ray particles access due to the altitude over sea level and high cutoff in the location. As we expected from a decreasing magnetic component and field intensity vector, we observed an increment in the access of particles in LARC, linked to the low values of its cutoff rigidity and secular decreasing of the magnetic field. LARC, OLC and OP had Rc values of 2.70, 9.52 and $11.71 \mathrm{GV}$ respectively in 2010 .

In order to calculate the trajectory of the particles, we considered only vertically incident protons for each station location, considering the top of the atmosphere at $20 \mathrm{~km}$ alti- 


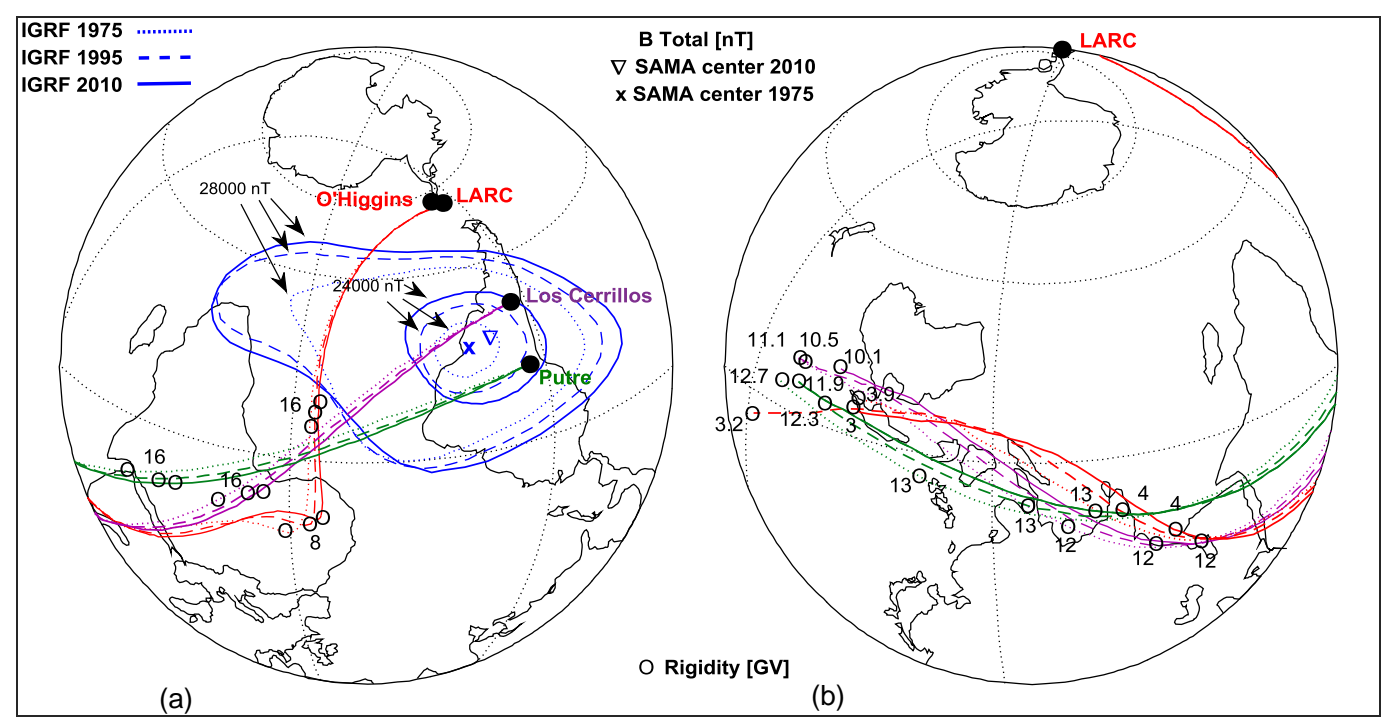

Figure 2. Geomagnetic $B$ total field intensity map, with the SAMA variability and the particle asymptotic arrival directions map for Putre, Los Cerrillos and LARC stations. The different line types mean asymptotic trajectories computed by magnetic models of the years 1975 , 1995 and 2010 (IGRF). (a) The variability of SAMA is represented by the set of lines over parts of South Africa, the Atlantic Ocean, South America and part of Pacific Ocean, where its center is located close to Buenos Aires and it is moving west. The variability of particle trajectories is also shown and depends on the spatiotemporal magnetic field configuration. (b) Minimum energy for entrance of asymptotic direction arrivals.

tude over each observatory. For the calculated upper $(\mathrm{Ru})$, lower (RL) and effective (Rc) cutoff rigidity, we used the program developed by Smart and Shea (2001). This method consists of using the sixth-order Runge-Kutta approximation in order to resolve the particle equation of motion to calculate several particle (asymptotic) trajectories arriving (allowed trajectory) or not (forbidden trajectory) at the Earth's surface from outer space, using different amounts of momentum per charge unit.

Due to the fact that different amounts of momentum per charge unit (rigidity) imply different trajectories, the upper (lower) rigidity $\mathrm{Ru}(\mathrm{RL})$ is defined as the maximum (minimum) value of rigidity where the allowed-forbidden transition is detected among the different sets of trajectories. While the effective rigidity is defined as the average between the upper and the lower rigidity (Smart and Shea, 2001; Storini et al., 2002; Bobik et al., 2003), Fig. 2 shows the arrivals of sets of particles obtained with numerical computations of the charged particle trajectories reaching OP, OLC and LARC observatories, with values close to $300 \mathrm{GV}$ in rigidity, using IGRF 1975, 1995 and 2010, where IGRF stands for "International Geomagnetic Reference Field" and corresponds to a mathematical model of the Earth's main field and its annual secular variation; each updated version of this model is released every 5 years (https://www.ngdc.noaa. gov/IAGA/vmod/igrf.html). For OP, the change in Ru values is approximately $-0.0225 \mathrm{GV} \mathrm{yr}^{-1}$, which may be associated with SAMA's westward drift. In general, the results of the calculations for vertical directions of particle access, generated at the top of the atmosphere (supposed $20 \mathrm{~km}$ altitude) with rigidities between 20.0 and $0.02 \mathrm{GV}$, produce obtained values for allowed and forbidden particles. The time variability of cutoffs shows the decreasing trend in the OP, LC and LARC observatories that can be visualized in three stripes:"upper" for an allowed-forbidden pair; "lower", which is related to geomagnetic effects; and "effective" cutoff, associated with penumbra regions, and the values that oscillate around the decreasing geomagnetic field (for more information, see Storini et al., 1999). The $\mathrm{Ru}$ values oscillated and decreased steadily; the annual variation in $\mathrm{Rc}$ is small $\left(-0.0217 \mathrm{GV} \mathrm{yr}^{-1}\right)$, while the value for $\mathrm{RL}$ is $-0.0200 \mathrm{GV} \mathrm{yr}^{-1}$, with a more predominant oscillation than the other rigidities (Storini et al., 1999). Values recorded at Los Cerrillos observatory decreased strongly as follows: $\mathrm{Ru}=-0.0285 \mathrm{GV} \mathrm{yr}^{-1}$, effective cutoff rigidity $\mathrm{Rc}=-0.0355 \mathrm{GV} \mathrm{yr}^{-1}$ and low cutoff rigidity $\mathrm{RL}=-0.0335 \mathrm{GV} \mathrm{yr}^{-1}$. Values recorded at LARC changed as follows: $\mathrm{Ru}=-0.0222 \mathrm{GV} \mathrm{yr}^{-1}, \mathrm{Rc}=-0.0200 \mathrm{GV} \mathrm{yr}^{-1}$ and $\mathrm{RL}=-0.0126 \mathrm{GV} \mathrm{yr}^{-1}$. Cutoff rigidity decrease is more pronounced between polar and medium latitudes, at approximately $63^{\circ}$ to $47^{\circ} \mathrm{S}$ (Fig. 3). Figure 3 shows changes in Rc values, which may be seen as the spatiotemporal changes in the shielding provided by the geomagnetic field against external charged particles. The values obtained show a decreasing cutoff rigidity trend between 18 and $63^{\circ} \mathrm{S}$ latitude along the Andes in the area near to the Chilean trench, going through the triple junction point, all the way to the Antarctic slab (Fig. 3). 


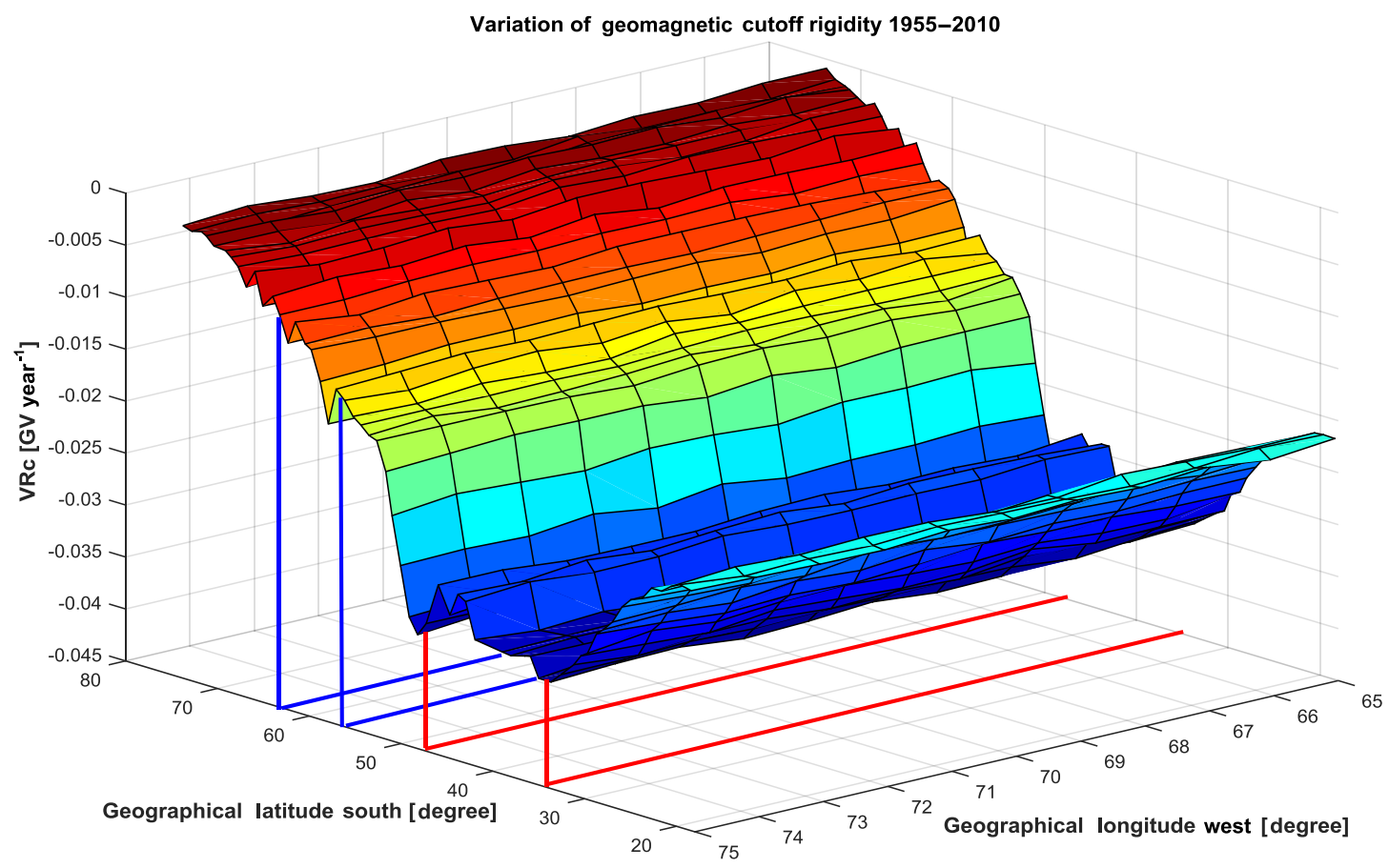

Figure 3. Values obtained for the variation rate of effective cutoff rigidity, related to special points on the Chilean coast in the geological model of Earth tectonic plates in the Southern Hemisphere. The red colors represent lower temporal changes in Rc in each location, while blue colors represent the maximum changes. The red lines indicate the latitudes of highest variation. Significant values were obtained at $46.5^{\circ} \mathrm{S}$, $76^{\circ} \mathrm{W}$ in the Taitao peninsula in Chile, which is the triple junction point of the Nazca, Antarctic and South American plates. Furthermore, there was a high variation rate in the effective cutoff rigidity $(-0.033)$ at $52^{\circ} \mathrm{S}, 76.5^{\circ} \mathrm{W}$ close to Puerto Natales, in the Magellan Strait in Chile, indicated by blue lines (right). The last blue line indicate the Antarctic continent.

Furthermore, significant points shown in Fig. 3 are $46.5^{\circ} \mathrm{S}, 76^{\circ} \mathrm{W}$, located on the peninsula of Taitao in Chile, which corresponds to the triple point junction of the Nazca, South America and Antarctic tectonic plates, and $53^{\circ} \mathrm{S}$, $76.5^{\circ} \mathrm{W}$, located in Puerto Natales, near the Strait of Magellan, which corresponds to the triple point formed by the Antarctic, Nova Scotia and South America tectonic plates. The Nazca-Nova Scotia border reaches $54^{\circ} \mathrm{S}$ in the Strait of Magellan. Another important area is located between 22 and $38^{\circ} \mathrm{S}$ latitude, where the greatest decrease in the variations of $\mathrm{Rc}$ is located, and which corresponds to the Atacama trench, with an estimated depth of $8000 \mathrm{~m}$.

\subsection{Magnetic field measurements behavior and the Sumatra, Maule and Tohoku earthquakes}

In the paper by Florindo and Alfonsi (1995), there is a chart showing the secular acceleration observed at the L'Aquila observatory and the date of occurrence for the 1960-1985 period. Other authors, such as Mouël and Courtillot (1981), have tried to obtain correlations between magnetic signals generated in the Earth's core and other geophysical phenomena, like the Earth minimum rotation and the occurrence of strong earthquakes.
The main feature in the South American region corresponds to the movement of the SAMA, implying a decrease in the cutoff rigidity trend. In Storini et al. (1999), and in Fig. 3 of this paper, we can see the geomagnetic cutoff rigidities rate variation between 1950 and 2010. Following the path indicated by the geomagnetic rigidity values at the bottom of the Southern Hemisphere, which contemplates the vertical component of the geomagnetic field, we find it necessary to study the largest seismic movements that occurred in this area of the planet, and the behavior of the magnetic field component $\mathrm{Bz}$ during these events. Specifically, the change in the magnetic field prior to the 2010 Maule event $\left(8.8 M_{\mathrm{w}}\right)$ was analyzed, as well as the events of Sumatra and Japan ( $>9 M_{\mathrm{w}}$ ), where the first and second derivative showed similar behavior. We then looked for significant frequencies between the jump in magnetic field values and the actual earthquakes.

The Bz component of the magnetic field, registered at the Putre station before and after the Maule earthquake, is shown in Fig. 4a, starting on 31 October 2009, up to 1 May 2010. The dotted red line indicates 27 February 2010, the day of the $8.8 M_{\mathrm{w}}$ quake, with its hypocenter located at $36^{\circ} 17^{\prime} 23^{\prime \prime} \mathrm{S}$, $73^{\circ} 14^{\prime} 20^{\prime \prime} \mathrm{W}$ at a depth of approximately $35 \mathrm{~km}$. Average variation of the magnetic field in the period of study was 
$65 \mathrm{nT}$, with a maximum variation of $180 \mathrm{nT}$. Rapid changes in the magnetic field are represented by a purple dotted line on 23 January 2010 (Fig. 4a). The Bz component experienced a decrease of more than $350 \mathrm{nT}$ between $18 \mathrm{Jan}$ uary 2010 and 23 January 2010; this period is important because it is useful to identify the change in the linear trend of the data, which is shown through the change in the $R$ squared values. These values change from 0.7581 to 0.3998 after this period. After the $R$-squared change, 36 days went by until the Maule event (Fig. 4a). The values for $\mathrm{dBz} / \mathrm{d} t$ are $15 \mathrm{nT}$ day $^{-1}$ on average, with its minimum right after the 27 February earthquake, at $10 \mathrm{nT} \mathrm{day}^{-1}$ and a maximum of $140 \mathrm{nT} \mathrm{day}^{-1}$, before the 23 February jump. The values for $\mathrm{d}^{2} \mathrm{Bz} / \mathrm{d} t^{2}$ have minimum and maximum of -10 and $160 \mathrm{nT}_{\text {day }}{ }^{-2}$, with an average of $25 \mathrm{nT} \mathrm{day}^{-2}$.

The seismological data for the 26 December 2004 Sumatra earthquake are as follows: $9.2 M_{\mathrm{w}}$ magnitude, location $3.316^{\circ} \mathrm{N}, 95.854^{\circ} \mathrm{E}$, and depth $30 \mathrm{~km}$. Magnetic values show erratic variations, since two earthquakes occurred in that area, on 26 December 2004 and 28 March 2005. Despite this, there are observable jumps on 22 August 2004 (dotted purple line), longer in duration than the one of the Maule event (130 and 36 days respectively). This jump in the magnetic data is viewed by the change in the $R$-squared values, from 0.5075 to 0.1312 (Fig. $4 \mathrm{~b}$ ); $\mathrm{dBz} / \mathrm{d} t$ has average values of $2.3 \mathrm{nT} \mathrm{day}^{-1}$, with its minimum value just after the $24 \mathrm{De}-$ cember event at $1.0 \mathrm{nT}$ day $^{-1}$ and a maximum of $8 \mathrm{nT}$ day $^{-1}$ after the 22 August 2004 jumps. Values for $\mathrm{d}^{2} \mathrm{Bz} / \mathrm{d} t^{2}$ have a minimum and maximum of 2.0 and $9.5 \mathrm{nT} \mathrm{day}^{-2}$, with an average value of $2.5 \mathrm{nT}$ day $^{-2}$.

The seismological data for the 11 March 2011 Tohoku, Japan earthquake are as follows: magnitude $-9.0 M_{\mathrm{w}}$, location $-38.322^{\circ} \mathrm{N}, 142.369^{\circ} \mathrm{E}$, and depth $-32 \mathrm{~km}$. The event was triggered by interaction between the Okhotsk and Pacific plates. Despite the existence of small geomagnetic events between January and March 2011, there is a distinguishable jump prior to the event (6 February, dotted purple line), similar to what happened at Maule (33 and 36 days respectively), where the change in the $R$-squared values also occurs, from 0.5252 to 0.7820 . (Fig. 4c). Values for $\mathrm{dBz} / \mathrm{d} t$ are on average $12 \mathrm{nT} \mathrm{day}^{-1}$, with a value just after the 11 March event of 20 and $4 \mathrm{nT} \mathrm{day}^{-1}$ after the 6 February jump; $\mathrm{d}^{2} \mathrm{Bz} / \mathrm{d} t^{2}$ have minimum and maximum values of 10 and $110 \mathrm{nT} \mathrm{day}^{-2}$, with an average of $22 \mathrm{nT}$ day $^{-2}$.

We used the fast Fourier transform analysis methods to calculate frequency for the Maule, Sumatra and Tohoku events. The graphical representation of the values of the spectral power densities is useful to compare and identify similarities between the seismic events.

The first spectral analysis corresponds to the use of data previously shown. Figure 5a shows the rising of a spectral band of lower frequencies which seems to be similar among the stations during the studied period. In order to corroborate this result, magnetic data from Kanoya station (Fig. 1 and Table 1) were used in contrast with the OP during the extended (a)

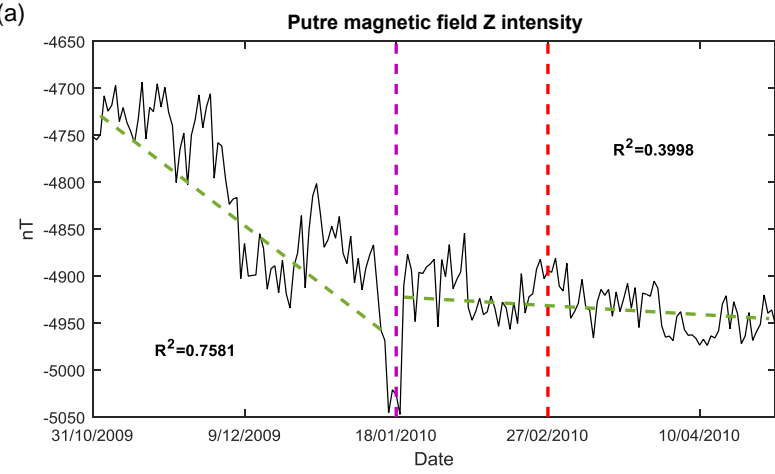

(b)
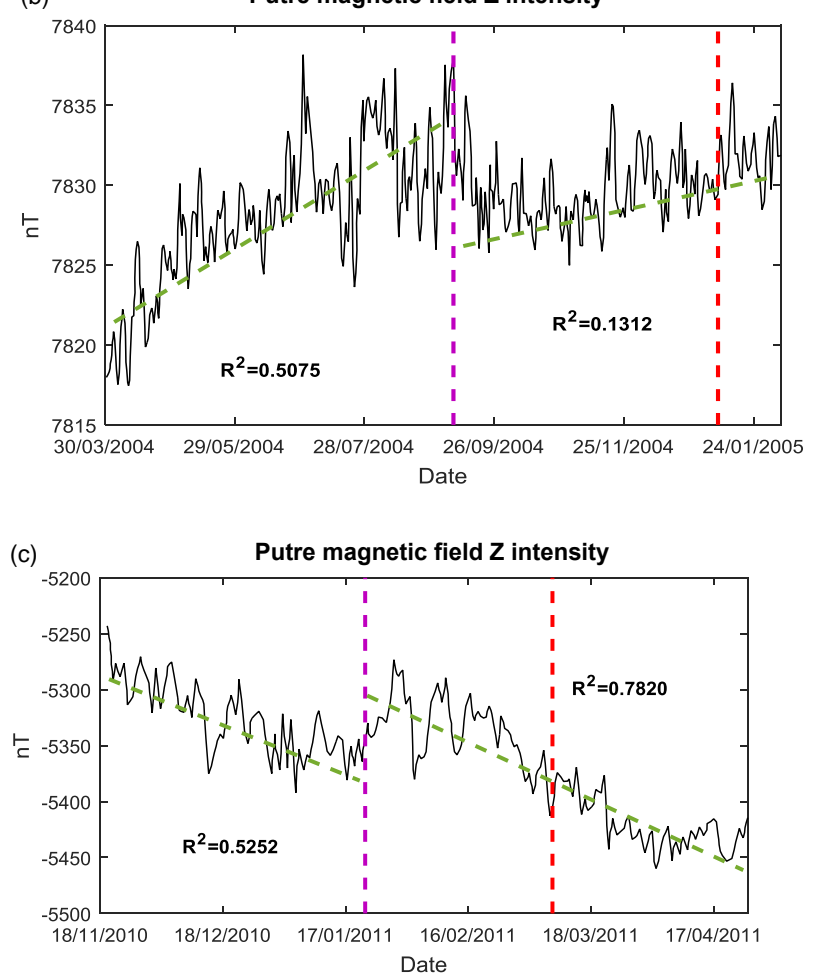

Figure 4. (a) Behavior of $B$ in Maule region, Chile, before and after 27 February 2010 seismic event (includes what precedes the jump, represented by the change in $R$-squared value) of 18 January 2010 . (b) Behavior of $B$ in Sumatra, before and after 26 December 2004 seismic event (includes what precedes the jump of 22 August 2004) and (c) behavior of $B$ in Tohoku, Japan, before and after 11 March 2011 seismic event, and what precedes the jump of 6 February 2011.

period of the Tohoku event (23 August 2010-5 May 2011). In all cases, the fundamental frequencies for daily averages are located between 5.680 and $3.510 \mu \mathrm{Hz}$ (period of $48.9 \mathrm{~h}$ to $79.13 \mathrm{~h}$ ).

The significant frequencies data are as follows:

- the Maule earthquake in Chile, detected in OP: 5.064, $4.747,5.154 \mu \mathrm{Hz}$ 
(a) $\times 10^{4} \quad$ FFT second derivative of $Z$ magnetic component

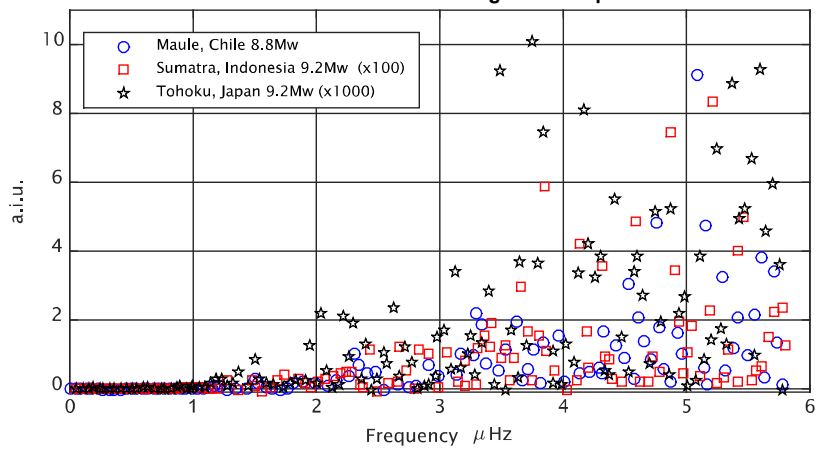

(b) $\times 10^{4}$ FFT second derivative of $Z$ magnetic component

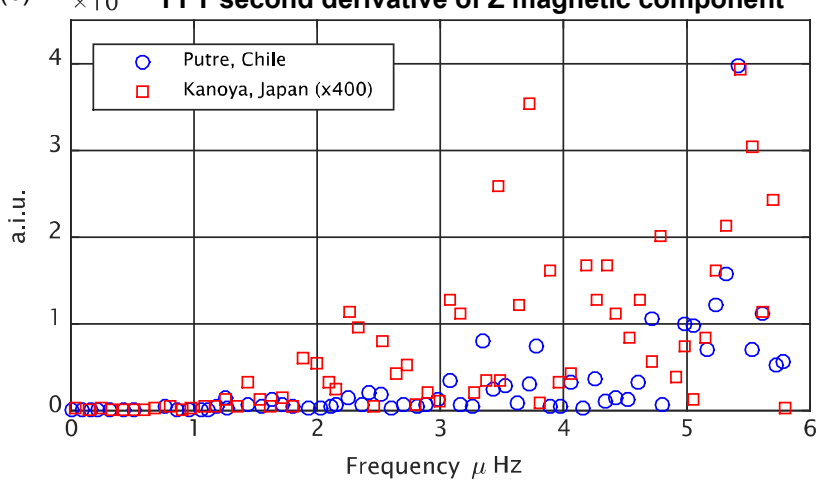

Figure 5. Fourier analysis of second derivative of $\mathrm{Bz}$ component, where the frequencies are on the order of microhertz. In (a) we show the significant frequencies for the earthquakes in Maule, Tohoku and Sumatra; panel (b) shows the significant frequencies for earthquake of Tohoku, recorded in Putre, Chile, and Kanoya, Japan, respectively. Both panels show the rising of a frequency band inside the 5.680 and $3.510 \mu \mathrm{Hz}$ range.

- the Tohoku earthquake in Japan, detected in Kanoya Station: $4.747,5.606,4.838 \mu \mathrm{Hz}$

- the Tohoku earthquake in Japan, detected in OP: 5.425, $5.333,5.606 \mu \mathrm{Hz}$

- the Sumatra earthquake in Indonesia, detected in Guam Station: $5.135,3.481,3.843 \mu \mathrm{Hz}$

The values of the frequencies of the earthquakes are 5.680, 5.414, 5.327, 5.226, 5.128, 5.144, 4.822, 4.777, 3.708 and $3.510 \mu \mathrm{Hz}$ (Fig. 5).

Additionally, the spectrogram analysis was used for the Maule earthquake. Using the daily average data range from 10 December 2009 to 29 April 2010 and then moving this range forward every 12 days with an overlap of $80 \%$. The results were used to make a 3-D graph for date, frequency and power spectral density, where date indicates the final day of the corresponding 12-day data range (Fig. 6). Figure 6 clearly shows that the highest values of power spectral density appear in the range 5.606 to $3.481 \mu \mathrm{Hz}$ (waves period $\sim 2$ to $\sim 3$ days) during the period before the Maule event (green to red peak colors), while the lower values appear after the occurrence of the event (blue shadow peaks), indicating that the earthquake event could be responsible for the change in behavior of the magnetic field.

\section{Discussion and conclusions}

Our main objective is to study the variations of the magnetic rigidity cutoff, earthquakes and movement of tectonic plates on the eastern Pacific coast in the Southern Hemisphere. In order to do so, we present the geomagnetic changes detected in that area.

Starting with the variations of the total magnetic field and its components, we verified the increasing influence of the phenomenon known as SAMA, with the decrease in the rate of change in rigidity cutoff obtained along the $70^{\circ} \mathrm{W}$ meridian, between the 18 and $42^{\circ} \mathrm{S}$ latitude (Fig. 3). The magnitude of decrease in magnetic field components is different depending on the specific location of the monitoring stations, but it is reflected simultaneously throughout the hemisphere. The magnetic field variation at both OP and OLC is greater and clearly shows its relation to SAMA, while the rate of change is smaller at O'Higgins and LARC (as they are not affected by SAMA).

The observatories are located on different tectonic plates: OP and OLC on the South American tectonic plate, LARC is on the Scotia tectonic plate and O'Higgins on the Antarctic tectonic plate. They measured changes in the magnetic field values, corroborating variations of the magnetic rigidity cutoff linked to the characteristics of the flat Chilean slab and the continuous approach of the South Atlantic magnetic anomaly (Fig. 1). In particular, the spatial and temporal variation of the effective magnetic cutoff rigidity and its relation with specific geographic coordinates in the tectonic plate is significant (Vertical lines in Fig. 3). This possible relation with the lithosphere can give us another tool for analyzing the model of the Earth's tectonic plates and geomagnetic models in the area.

In the case of the 2010 Maule event, Fig. 4a shows a continuous decrease of the $\mathrm{Bz}$ component of the magnetic field up to 36 days before the earthquake, where the $R$-square value changed. Taking into consideration the similarities found in the values of the Bz component in the time between the jumps (change in $R$-square value) and the Maule, Sumatra and Japan events of 36, 130 and 33 days (with variations smaller than $100 \mathrm{nT}$ ) (Fig. 4), we decided to conduct a spectral analysis first for the Maule, and then for the Sumatra and Tohoku events.

After the analysis, the fundamental frequencies detected were in the range of 5.606 to $3.481 \mu \mathrm{Hz}$, as shown in Fig. 5 . The Sumatra earthquake is different though, since it involved two additional earthquakes over $7 M_{\mathrm{w}}$. In particular, the significant frequencies observed in OP for the Maule and Tohoku events range from 5.611 to $5.227 \mu \mathrm{Hz}$, while the Suma- 


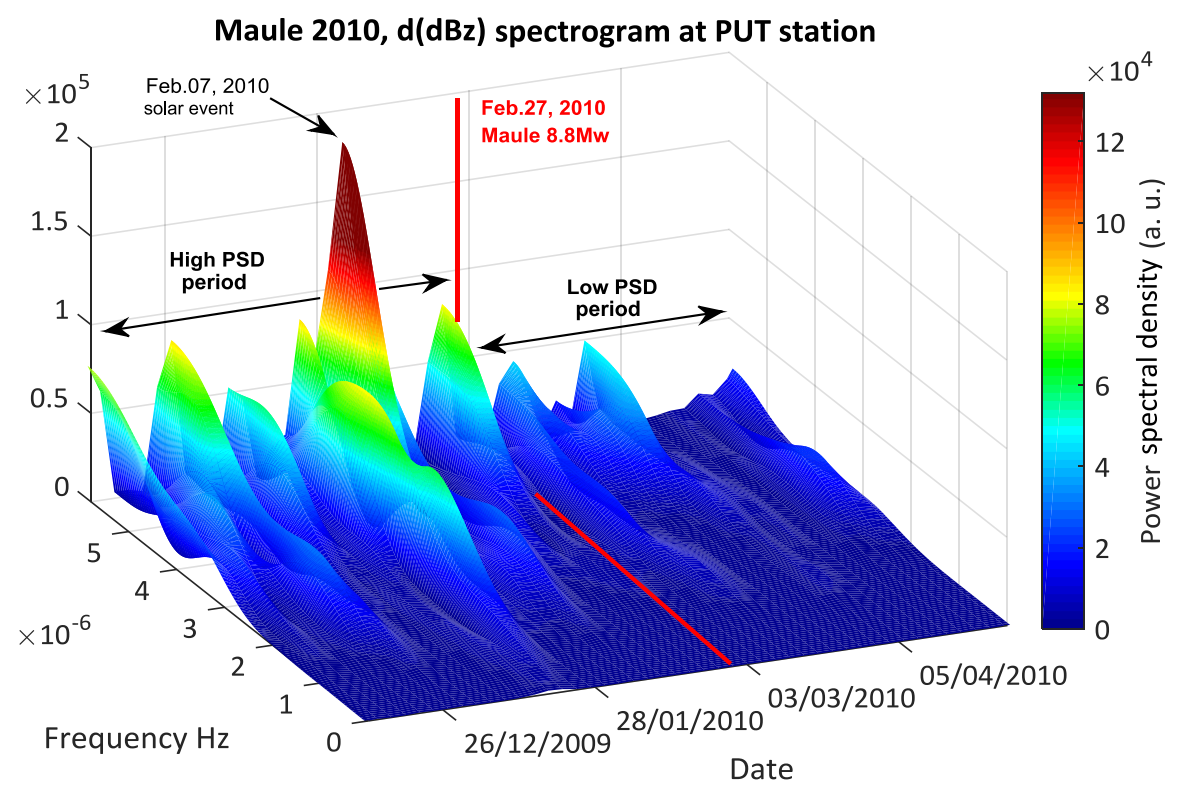

Figure 6. Spectrogram of Bz second temporal derivative. The Maule event date is marked in red, where the period before the earthquake event is characterized by high power spectral density values (red colors) and the values after the earthquake are clearly lower (blue colors). The February solar event is also marked (Dröge et al., 2014).

tra frequencies, ranging from 4.822 to $3.708 \mu \mathrm{Hz}$, indicate differences between the Sumatra event and the other studied earthquakes. Furthermore, a spectrogram analysis carried out for the Maule 2010 event showed that the change in the spectral density power in the range of $\mu \mathrm{Hz}$ could be related to the occurrence of the Maule event, as shown in Fig. 6.

After conducting the analysis, we attempted to identify the origin of the geomagnetic characteristics. We distinguished two systems; one of them could be associated with the coremantle operating deep within the Earth, and another one related to the tectonic plates operating near the surface of the Earth, at depths between 20 and $65 \mathrm{~km}$.

The core-mantle system generates magnetic anomalies as SAMA due to the abrupt change in the topography of CMB (Pavón-Carrasco and De Santis, 2016), which in turn affects the magnetic cutoff rigidity (Herbst et al., 2013). Furthermore, the energy released by the movement of tectonic plates could affect the top layers of core fluid (Gubbins, 1988). One of the first explanations was given by Florindo et al. (1995, 2005), relating abrupt topographic modifications to anomalous behavior of geomagnetic fields. Mullan (1973) theorizes that the large seismic activity in the Pacific Ring of Fire could be generated at great depths. In the same line, Florindo and Alfonsi (1995), thought that seismic events could be linked to abrupt topographic changes at the $\mathrm{CMB}$, which generated magnetic variations through the mantle. Another possible explanation of this apparent link between magnetic field, cutoff rigidity and geological systems arises from the instabilities in the CMB that are able to produce secular variations in the magnetic field on the Earth surface, and that corresponds to non-dipolar evolution of the geodynamo (Constable, 2007), since the topography of the CMB is significant in subduction zones, where the subducted slabs can generate downwelling or sinkholes in the deeper areas of the mantle and upwelling or outcrops in areas of divergence (Heirtzler, 2002; Koper, 2003; Hartmann and Pacca, 2009; Lassak et al., 2010; Calkins et al., 2012; Koelemeijer et al., 2012; Bayanjargal, 2013; Tarduno et al., 2015; Pavón-Carrasco and De Santis, 2016; Terra-Nova et al., 2016). However, the latest research on magnetic field and seismicity seems to come from the socalled lithosphere-atmosphere-ionosphere coupling (LAIC) (Hayakawa et al., 2015; De Santis et al., 2015, 2017; Contoyiannis et al., 2016; Potirakis et al., 2016a, b; Oikonomou et al., 2017).

The more superficial system occurs in the lithosphere, due to fractures in the rock that end up generating a wide spectrum of low frequencies in the magnetic field and are possibly associated with earthquakes (Donner et al., 2015). These changes in the magnetic field were studied by Florindo et al. (1996) while they analyzed the 1964 Alaska earthquake. Such studies, along with a possible correlation between variation in magnetic cutoff rigidity and tectonic plates, motivated the study of the relation between magnetism and earthquakes presented in the previous sections, for events like the 2010 Maule earthquake, and also using data from the 2004 Sumatra and 2011 Tohoku events. This makes sense if we consider the goals of the latest research that links magnetic activity of internal origin with some seismic events (including the 2011 Tohoku quake), several days or even weeks in advance of the earthquakes (Hayakawa 
and Molchanov, 2002; Pulinets and Boyarchuk, 2004; Varotsos, 2005; Molchanov and Hayakawa, 2008; Liu, 2009; Hayakawa et al., 2015; De Santis et al., 2015, 2017; Contoyiannis et al., 2016; Potirakis et al., 2016a, b). Even more, the frequencies shown in Figs. 5 and 6 show a spectrum $(\sim \mu \mathrm{Hz})$ lower than that studied by Hayakawa et al. (2015), De Santis et al. (2015), Contoyiannis et al. (2016), Potirakis et al. (2016a, b) and De Santis et al. (2017) (on the order of millihertz).

The upwelling of frequencies in the microhertz range detected in the three stations could be normal before the three seismic events. It could be related to the fact that the only one common feature among the three earthquakes is that all of them were identified as megathrust events into a subducting lithospheric configuration. Furthermore, it is also important to point out that the frequency range studied by the seismomagnetic community corresponds to millihertz, whilst this study showed the microhertz frequency range. This would be in agreement with the theoretical computations carried out by Vallianatos and Tzanis (2003), where the ultralow frequency band reaches 3 orders of magnitude at least.

Finally, we understand that the relation between geomagnetism and geodynamics is currently a controversial topic, and because of that we have been careful with these issues, since in recent years a number of groups have emerged linking magnetism and seismicity. Despite this, we believe future work must be conducted in order to achieve a full understanding of the phenomena presented in this work.

Data availability. The magnetic data recorded by Chilean stations and abroad are open-source and can be found at http://supermag. jhuapl.edu/mag/? selecting the stations in the list. In case of problems, the data can also be requested from the main author.

Competing interests. The authors declare that they have no conflict of interest.

Acknowledgements. We thank the anonymous referee and Masashi Hayakawa and Georgios Balasis for their advice in order to improve our paper. The authors also thank Eftyhia Zesta (UCLA-IGPP) and Luis Alberto Raggi (Incas-U. Chile) for their collaboration and support. We also thank the collaboration of Daniel Gálvez and Juan Carlos Lisboa. The fluxgate magnetometer at Putre-Incas observatory is partially supported by FCFM at the University of Chile, in collaboration with the South American Magnetometer B-Field Array (SAMBA/AMBER) project of the University of California, Los Angeles, USA, and University of Tarapacá University, Chile. The LARC observatory is supported by the Chile-Italy Collaboration via the University of Chile and PNRA (Italy), and INACh partial support. The results presented in this paper rely on data collected at magnetic observatories. We thank the national institutes that support them and INTERMAGNET for promoting high standards of magnetic observatory practice (www.intermagnet.org). David Laroze acknowledges partial financial support from CONICYT-ANILLO ACT 1410, Yachay Tech startup, and centers of excellence with BASAL/CONICYT financing, grant FB0807, CEDENNA.

The topical editor, Georgios Balasis, thanks two anonymous referees for help in evaluating this paper.

\section{References}

Anand, K. C., Daniel, R. R., Stephens, S. A., Bhowmik, B., Krishna, C. S., Aditya, P. K., and Puri, R. K.: Rigidity spectrum of cosmic ray helium nuclei, P. Indian Acad. Sci., 67, 138-154, 1968.

Bayanjargal, G.: The study of westward drift in the main geomagnetic field, International Journal of Geophysics, 2013, 202763, https://doi.org/10.1155/2013/202763, 2013.

Bobik, P., Storini, M., Kudela, K., and Cordaro, E. G.: Cosmicray transparency for a medium-latitude observatory, Società Italiana di Fisica, Il Nuovo Cimento C, 026, , p. 177, Marzo-Aprile, 2003.

Calkins, M. A., Noir, J., Eldredge, J. D., and Aurnou, J. M.: The effects of boundary topography on convection in Earth's core, Geophys. J. Int., 189, 799-814, https://doi.org/10.1111/j.1365246X.2012.05415.x, 2012.

Constable, C.: Non-dipole field, in: Encyclopedia of Geomagnetism and Paleomagnetism, edited by: Gubbins, D. and HerreraBervera, E., Springer, Dordrecht, the Netherlands, 2007.

Contoyiannis, Y., Potirakis, S. M., Eftaxias, K., Hayakawa, M., and Schekotov, A.: Intermittent criticality revealed in ULF magnetic fields prior to the 11 March 2011 Tohoku earthquake $\left(M_{\mathrm{W}}=9\right)$, Physica A, 452, 19-28, https://doi.org/10.1016/j.physa.2016.01.065, 2016.

Cordaro, E. G., Laroze. D., Olivares. E. F., Galvez, D., and Salazar, D.: New 3He neutron monitor for Chilean cosmic rays observatories from Altiplanic zone to Antarctic zone, Adv. Space Res., 49, 1670-1683, 2012.

De Santis, A., De Franceschi, G., Spogli, L., Perrone, L., Alfonsi, L., Qamili, E., Cianchini, G., Di Giovambattista, R., Salvi, S., Filippi, E., Pavón-Carrasco, F. J., Monna, S., Piscini, A., Battiston, R., Vitale, V., Picozza, P. G., Conti, L., Parrot, M., Pinçon, J.-L., Balasis, G., Tavani, M., Argan, A., Piano, G., Rainone, M. L., Liu, W., and Tao, D.: Geospace perturbations induced by the Earth: the state of the art and future trends, Phys. Chem. Earth, 85-86, 17-33, https://doi.org/10.1016/j.pce.2015.05.004, 2015.

De Santis, A., Balasis, G., Pavón-Carrasco, F. J., Cianchini, G., and Mandea, M.: Potential earthquake precursory pattern from space: the 2015 Nepal event as seen by magnetic Swarm satellites, Earth Planet. Sc. Lett., 461, 119-126, https://doi.org/10.1016/j.epsl.2016.12.037, 2017.

Donner, R. V., Potirakis, S. M., Balasis, G., Eftaxias, K., and Kurths, J.: Temporal correlation patterns in pre-seismic electromagnetic emissions reveal distinct complexity profiles prior to major earthquakes, Phys. Chem. Earth, 85-86, 44-55, https://doi.org/10.1016/j.pce.2015.03.008, 2015.

Dröge, W., Kartavykh, Y. Y., Dresing, N., Heber, B., and Klassen, A.: Wide longitudinal distribution of interplanetary 
electrons following the 7 February 2010 solar event: observations and transport modeling, J. Geophys. Res.-Space, 119, 60746094, https://doi.org/10.1002/2014JA019933, 2014.

Fichtner, H., Heber, B., Herbst, K., Kopp, A., and Scherer, K.: Solar activity, the heliosphere, cosmic rays and their impact on the Earth's atmosphere, in: Climate And Weather of the SunEarth System (CAWSES): Highlights from a Priority Program, edited by: Lübken, F.-J., Springer, Dordrecht, the Netherlands, 55-78, 2012.

Florindo, F. and Alfonsi, L.: Strong earthquakes and geomagnetic jerks: a cause-effect relationship?, Ann. Geofis., 38, 457-461, 1995.

Florindo, F., Alfonsi, L., Piersanti, A., Spada, G., and Marzocchi, W.: Geomagnetic jerks and seismic activity, Ann. Geofis., 39, 1227-1233, https://doi.org/10.4401/ag-4049, 1996.

Florindo, F., De Michelis, P., Piersanti, A., and Boschi, E.: Could the $M_{\mathrm{W}}=9.3$ Sumatra earthquake trigger a geomagnetic jerk?, EOS Transactions American Geophysical Union, 86, 123-124, https://doi.org/10.1029/2005EO120004, 2005.

Gubbins, D.: Thermal core-mantle interactions and time-averaged paleomagnetic field, J. Geophys. Res., 93, 3413-3420, 1988.

Hartmann, G. A. and Pacca, I. G.: Time evolution of the South Atlantic Magnetic Anomaly, Ann. Braz. Acad. Sci., 81, 243-255, https://doi.org/10.1590/S0001-37652009000200010, 2009.

Hayakawa, M. and Molchanov, O. A. (Eds.): Seismo Electromagnetics: Lithosphere-Atmosphere-Ionosphere Coupling, TERRAPUB, Tokyo, 2002.

Hayakawa, M., Hattori, K., and Ohta, K.: Monitoring of ULF (Ultra low frequency) geomagnetic variations associated with earthquakes, Sensor, 7, 1108-1122, 2007.

Hayakawa, M., Schekotov, A., Potirakis, S., and Eftaxias, K.: Criticality features in ULF magnetic fields prior to the 2011 Tohoku earthquake, P. Jpn. Acad. B-Phys., 91, 25-30, https://doi.org/10.2183/pjab.91.25, 2015.

Heirtzler, J. R.: The future of the South Atlantic anomaly and implications for radiation damage in space, J. Atmos. Sol.-Terr. Phy., 64, 1701-1708, https://doi.org/10.1016/s1364-6826(02)001207, 2002.

Herbst, K., Kopp, A., and Heber, B.: Influence of the terrestrial magnetic field geometry on the cutoff rigidity of cosmic ray particles, Ann. Geophys., 31, 1637-1643, https://doi.org/10.5194/angeo31-1637-2013, 2013.

Koelemeijer, P. J., Deuss, A., and Trampert, J.: Normal mode sensitivity to Earth's D" layer and topography on the core-mantle boundary: what we can and cannot see, Geophys. J. Int., 190, 553-568, 2012.

Koper, K. D., Pyle, M. L., and Franks, J. M.: Constraints on aspherical core structure from PKiKP-PcP differential travel times, J. Geophys. Res., 108, 2168, https://doi.org/10.1029/2002JB001995, 2003.

Kopytenko, Y. A., Ismaguilov, V. S., Hattori, K., and Hayakawa, M.: Anomaly disturbances of the magnetic fields before the strong earthquake in Japan on 11 March 2011, Ann. Geophys.-Italy, 55, 101-107, https://doi.org/10.4401/ag-5260, 2012.

Lassak, T., McNamara, A., Garnero, E., and Zhong, S.: Coremantle boundary topography as a possible constraint on lower mantle chemistry and dynamics, Earth Planet. Sc. Lett., 289, 232-241, 2010.
Liu, J. Y.: Earthquake precursors observed in the ionospheric Fregion, in: Electromagnetic Phenomena Associated with Earthquakes, edited by: Hayakawa, M., Transworld Research Network, Trivandrum, India, 187-204, 2009.

Love, J. J. and Thomas, J. N.: Insignificant solar-terrestrial triggering of earthquakes, Geophys. Res. Lett., 40, 1165-1170, https://doi.org/10.1002/grl.50211, 2013.

Masci, F. and Thomas, J. N.: Are there new findings in the search for ULF magnetic precursors to earthquakes?, J. Geophys. Res.-Space, 120, 10289-10304, https://doi.org/10.1002/2015JA021336, 2015.

Molchanov, O. A. and Hayakawa, M.: Seismo Electromagnetics and Related Phenomena: History and Latest Results, TERRAPUB, Tokyo, 2008.

Mouël, J. L. and Courtillot, V.: Core motions, electromagnetic core-mantle coupling and variations in the Earth's rotation: new constraints from geomagnetic secular variation impulses, Phys. Earth Planet. In., 24, 236-241, 1981.

Mullan, D. J.: Earthquake waves and geomagnetic dynamo, Science, 181, 553-554, 1973.

Oikonomou, C., Haralambous, H., and Muslim, B.: Investigation of ionospheric precursors related to deep and intermediate earthquakes based on spectral and statistical analysis, Adv. Space Res., 59, 587-602, https://doi.org/10.1016/j.asr.2016.10.026, 2017.

Olsen, N., Luehr, H., Sabaka, T. J., Michaelis, I., Rauberg, J., and Tøffner-Clausen, L.: The CHAOS-4 geomagnetic field model, Geophys. J. Int., 197, 815-827, 2014.

Pavón-Carrasco, F. J. and De Santis, A.: The South Atlantic Anomaly: the key for a possible geomagnetic reversal, Front. Earth Sci., 4, 1-9, https://doi.org/10.3389/feart.2016.00040, 2016.

Potirakis, S., Eftaxias, K., Schekotov, A., Yamaguchi, H., and Hayakawa, M.: Criticality features in ultra-low frequency magnetic fields prior to the 2013 M6.3 Kobe earthquake, Ann. Geophys.-Italy, 59, S0317, https://doi.org/10.4401/ag6863, 2016a.

Potirakis, S. M., Hayakawa, M., and Schekotov, A.: Fractar analysis of the ground-recorded ULF magnetic field prior to the 11 March 2011 Tohoku earthquake $\left(M_{\mathrm{W}}=9\right)$ : discriminating possible earthquake precursors from space-sourced disturbance, Nat. Hazards, 85, 59-86, https://doi.org/10.1007/s11069-0162558-8, 2016b.

Pulinets, S. and Boyarchuk, K.: Ionospheric Precursors of Earthquakes, Springer, Berlin, 2004.

Smart, D. F. and Shea, M. A.: Geomagnetic Cutoff Rigidity Computer Program: Theory, Software Description and Example, NASA Technical Reports Serve, Final Report, 199 pp., 18 January 2001, ID: 20010071975, 2001.

Smart, D. F. and Shea, M. A.: World Grid of Calculated Cosmic Ray Vertical Cutoff Rigidities for Epoch 2000.0, Proceedings of the 30th International Cosmic Ray Conference, Mexico City, Mexico, 2008, Vol. 1 (SH), 737-740, 2008.

Soldati, G., Boschi, L., and Forte, A. M.: Tomography of core-mantle boundary and lowermost mantle coupled by geodynamics, Geophys. J. Int., 189, 730-746, https://doi.org/10.1111/j.1365-246X.2012.05413.x, 2012.

Storini, M., Shea, M. A., Smart, D. F., and Cordaro, E. G.: Cutoff Variability for the Antarctic Laboratory for Cosmic Rays 
(LARC: 1955-1995), Proceedings of the 26th International Cosmic Ray Conference, 17-25 August 1999, Salt Lake City, Utah, USA, International Union of Pure and Applied Physics (IUPAP), Volume 7, p. 402, 1999.

Storini, M., Smart, D. F., and Shea, M. A.: Summary of LARC Particle Asymptotic Changes from Geomagnetic Reference Field Model 1955 to 1955, Conference Proceedings Vol. 80, Italian Research on Antartic Atmosphere, edited by: Colacino, M., SIF, Bologna, 2002.

Takla, E. M., Yumoto, K., Okano, S., Uozumi, T., and Abe, S.: The signature of the 2011 Tohoku Mega earthquake on the geomagnetic field measurements in Japan, MRIAG, Journal of Astronomy and Geophysics, 2, 185-195, 2013.

Tarduno, J. A., Watkeys, M. K., Huffman, T. N., Cottrell, R. D., Blackman, E. G., Wendt, A., Scribner, C. A., and Wagner, C. L.: Antiquity of the South Atlantic Anomaly and evidence for top-down control on the geodynamo, Nat. Commun., 6, 7865, https://doi.org/10.1038/ncomms8865, 2015.

Terra-Nova, F., Amit, H., Hartmann, G. A., and Trindade, R. I. F. Using archaeomagnetic field models to constrain the physics of the core: robustness and preferred locations of reversed flux patches, Geophys. J. Int., 206, 1890-1913, https://doi.org/10.1093/gji/ggw248, 2016.
Thomas, J. N., Love, J. J., and Johnston, M. J. S.: On the reported magnetic precursor of the 1989 Loma Prieta earthquake, Phys. Earth Planet. In., 173, 207-215, https://doi.org/10.1016/j.pepi.2008.11.014, 2009.

Vallianatos, F. and Tzanis, A.: On the nature, scaling and spectral properties of pre-seismic ULF signals, Nat. Hazards Earth Syst. Sci., 3, 237-242, https://doi.org/10.5194/nhess-3237-2003, 2003.

Varotsos, P. A.: The Physics of Seismic Electric Signals, TERRAPUB, Tokyo, 2005.

Yoshida, M.: Core-mantle boundary topography estimated from numerical simulations of instantaneous mantle flow, Geochem. Geophy. Geosy., 9, Q07002, https://doi.org/10.1029/2008GC002008, 2008. 